\title{
Lower limb malformation-hypospadias syndrome
}

INSERM

\section{Source}

INSERM. (1999). Orphanet: an online rare disease and orphan drug data base. Lower limb malformation-hypospadias syndrome. ORPHA:2487

Lower limb malformation-hypospadias syndrome is a rare developmental defect during embryogenesis characterized by severe, uni- or bilateral lower limb malformations (incl. tibial hypoplasia, split and rocker bottom-shaped feet, and oligosyndactyly), normal upper limbs and hypospadias. Additional dysmorphic features (e.g. short neck and low-set, large ears), atrial septal defect, ureteropelvic junction stenosis and slight septation of the spleen, have also been reported. There have been no further descriptions in the literature since 1977. 